\title{
Correction to: Persistent physical symptoms reduction intervention: a system change and evaluation in secondary care (PRINCE secondary) - a CBT-based transdiagnostic approach: study protocol for a randomised controlled trial
}

\author{
Trudie Chalder ${ }^{1 * \dagger}$, Meenal Patel ${ }^{1 \dagger}$, Kirsty James ${ }^{2}$, Matthew Hotopf ${ }^{1}$, Philipp Frank ${ }^{3}$, Katie Watts ${ }^{1}$, Paul McCrone ${ }^{4}$, \\ Anthony David ${ }^{5}$, Mark Ashworth ${ }^{6}$, Mujtaba Husain${ }^{7}$, Toby Garrood $^{8}$, Rona Moss-Morris ${ }^{9 \dagger}$ and Sabine Landau ${ }^{2+}$
}

Correction to: BMC Psychiatry 19, 307 (2019)

https://doi.org/10.1186/s12888-019-2297-y

Following publication of the original article [1], the authors identified a typographical error in the proposed sample size section. The correct sentence is given below.

'The sample size calculation (Stata command sampsi) suggests that 161 patients per arm (322 in total) are needed to detect this effect size or a larger one with 90.14\% power allowing for a deflation for including baseline measures in the analysis model (factor 0.84 assuming a correlation between baseline and 52 weeks WSAS of $0.4)$ and an attrition rate of $25 \%$ '.

\section{Author details}

'Department of Psychological Medicine, Institute of Psychiatry, Psychology and Neuroscience, King's College London, 16 De Crespigny Park, London SE5 8AF, UK. ${ }^{2}$ Department of Biostatistics and Health Informatics, Institute of Psychiatry, Psychology and Neuroscience, King's College London, London,
UK. ${ }^{3}$ Department of Behavioural Science and Health, University College London, London, UK. ${ }^{4}$ Health Economics, Institute of Psychiatry, Psychology and Neuroscience, King's College London, London, UK. ${ }^{5}$ Division of Psychiatry, University College London, London, UK. ${ }^{6}$ Population Health and Environmental Sciences, Faculty of Life Sciences and Medicine, King's College London, London, UK. 'South London and Maudsley NHS Foundation Trust, London, UK. ${ }^{8}$ Department of Rheumatology, Guy's and St Thomas' NHS Foundation Trust, London, UK. ${ }^{9}$ School of Health Psychology Section, Institute of Psychiatry, Psychology and Neuroscience, King's College London, London, UK.

Published online: 12 August 2020

Reference

1. Chalder T, et al. Persistent physical symptoms reduction intervention: a system change and evaluation in secondary care (PRINCE secondary) - a CBT-based transdiagnostic approach: study protocol for a randomised controlled trial. BMC Psychiatry. 2019;19:307. https://doi.org/10.1186/s12888019-2297-y.

The original article can be found online at https://doi.org/10.1186/s12888019-2297-y.

* Correspondence: trudie.chalder@kcl.ac.uk

${ }^{\dagger}$ Trudie Chalder, Meenal Patel, Rona Moss-Morris and Sabine Landau contributed equally to this work.

'Department of Psychological Medicine, Institute of Psychiatry, Psychology and Neuroscience, King's College London, 16 De Crespigny Park, London SE5 $8 \mathrm{AF}, \mathrm{UK}$

Full list of author information is available at the end of the article

C The Author(s). 2020 Open Access This article is licensed under a Creative Commons Attribution 4.0 International License, which permits use, sharing, adaptation, distribution and reproduction in any medium or format, as long as you give appropriate credit to the original author(s) and the source, provide a link to the Creative Commons licence, and indicate if changes were made. The images or other third party material in this article are included in the article's Creative Commons licence, unless indicated otherwise in a credit line to the material. If material is not included in the article's Creative Commons licence and your intended use is not permitted by statutory regulation or exceeds the permitted use, you will need to obtain permission directly from the copyright holder. To view a copy of this licence, visit http://creativecommons.org/licenses/by/4.0/ The Creative Commons Public Domain Dedication waiver (http://creativecommons.org/publicdomain/zero/1.0/) applies to the data made available in this article, unless otherwise stated in a credit line to the data. 